\title{
Imperfuração anal associada à agenesia parcial do sacro e lipoma pré-sacral: síndrome de Currarino
}

\author{
Imperforate anus associated with partial sacral agenesis and presacral lipoma: Currarino syndrome
}

\author{
Paulo Ricardo G. Zen', Felipe Nora de Moraes ${ }^{3}$, Marina Boff Lorenzen³, Rafael Fabiano M. Rosa², Carla Graziadio4, Luiz Eduardo \\ Franciosi ${ }^{5}$, Giorgio Adriano Paskulin ${ }^{6}$
}

\section{RESUMO}

Objetivo: Relatar o caso de uma criança com síndrome de Currarino diagnosticada após avaliação por episódios recorrentes de infecção urinária.

Descrição do caso: Menina branca de dois anos, única filha de pais hígidos e sem história familiar de defeitos congênitos. A criança nasceu com imperfuração anal e com fístula retovestibular diagnosticadas no primeiro dia de vida. Por volta dos sete meses, começou a apresentar episódios recorrentes de infecção urinária, estabelecendo-se o diagnóstico de bexiga neurogênica. Na mesma ocasião, foi constatada a presença de agenesia parcial do sacro. A avaliação pela tomografia computadorizada e ressonância nuclear magnética de coluna identificou presença de fístula coincidente com a fosseta da transição lombo-sacral, observada ao exame físico; amputação da porção inferior da medula, com diminuição do número de raízes nervosas da cauda equina e massa présacral de aspecto lipomatoso. Esta foi confirmada durante a cirurgia de correção do ânus imperfurado. A criança não apresentava outras dismorfias e a avaliação radiológica dos pais não identificou anormalidades sacrais.

Comentários: A síndrome de Currarino é uma doença genética autossômica, dominante e rara caracterizada pela tríade formada por atresia anal, agenesia parcial do sacro e tumoração pré-sacral. Inclui teratomas, meningoceles, cistos entéricos e lipomas, como observado em nossa paciente. Crianças apresentando anormalidades anorretais deveriam ser sempre cuidadosamente avaliadas quanto à presença da síndrome de Currarino. A agenesia parcial do sacro é um forte indicativo da doença.

Palavras-chave: ânus imperfurado; lipoma; sacro; doenças da medula espinhal; genética.

\section{ABSTRACT}

Objective: To report a patient with Currarino syndrome diagnosed after evaluation for recurrent urinary infections.

Case description: This is a Caucasian two-year-old girl, the only daughter of healthy unrelated parents with no family history of congenital defects. The patient was born with imperforate anus and recto-vestibular fistula diagnosed in the first day after birth. At seven months of age, she started to present episodes of recurrent urinary infections and received a diagnosis of neurogenic bladder. At the same time, partial sacral agenesis was noted. Magnetic resonance imaging and computed tomography scan of the spine identified the presence of a fistula coincident with the lombo-sacral dimple described at clinical examination, amputation of the lower portion of the spinal cord with reduced number of nervous roots of the caudus equinus and lipomatous presacral mass.
Instituição: Universidade Federal de Ciências da Saúde de Porto Alegre (UFCSPA) e Complexo Hospitalar Santa Casa de Porto Alegre (CHSCPA), Porto Alegre, RS, Brasil

'Doutor em Patologia pela UFCSPA; Professor Adjunto da Disciplina de Genética Clínica e do Programa de Pós-Graduação em Patologia da UFCSPA; Porto Alegre, RS, Brasil

${ }^{2}$ Doutorando em Patologia da UFCSPA; Geneticista Clínico da UFCSPA e CHSCPA, Porto Alegre, RS, Brasil

${ }^{3}$ Acadêmico do Curso de Medicina da UFCSPA, Porto Alegre, RS, Brasil ${ }^{4}$ Mestre em Genética e Biologia Molecular da Universidade Federal do Rio Grande do Sul (UFRGS); Professora Assistente da Disciplina de Genética Clínica da UFCSPA; Porto Alegre, RS, Brasil

${ }^{5}$ Cirurgião Pediátrico do Hospital da Criança Santo Antônio (HCSA) e do CHSCPA, Porto Alegre, RS, Brasil
${ }^{6}$ Doutor em Genética e Biologia Molecular da UFRGS; Professor Associado da Disciplina de Genética Clínica da UFCSPA; Porto Alegre, RS, Brasil

Endereço para correspondência:

Giorgio Adriano Paskulin

Rua Sarmento Leite, 245, sala 403 - Centro

CEP 90050-170 - Porto Alegre/RS

E-mail: paskulin@ufcspa.edu.br

Conflito de interesse: nada a declarar

Recebido em: 9/7/2009

Aprovado em: 26/10/2009 
The patient did not present other dysmorphia. Parental radiologic evaluation did not identify sacral abnormalities.

Comments: Currarino syndrome is a rare autosomal dominant genetic disease characterized by the triad composed of anal atresia, partial sacral agenesis and presacral tumor. It includes, among others, teratomas, meningoceles, enteric cysts and lipomas, as observed in our patient. Children presenting anorectal abnormalities should be evaluated regarding the presence of Currarino syndrome. The partial sacral agenesis is a major sign of this disease.

Key-words: anus, imperforate; lipoma; sacrum; spinal cord diseases; genetics.

\section{Introdução}

A síndrome de Currarino (SC) (OMIM 176450) $)^{(1)}$, também conhecida como agenesia sacral hereditária ou ASP (Anal atresia; Sacral anomalies e Presacral mass), é uma doença genética autossômica dominante rara caracterizada clinicamente pela tríade formada por agenesia parcial do sacro, tumoração pré-sacral e malformação anorretal ${ }^{(2-4)}$. Apesar de descrita inicialmente em 1838 por Bryant, foi somente caracterizada como uma anomalia da embriogênese mais de um século depois, em 1981, por Currarino et a ${ }^{(5)}$. O espectro clínico da síndrome pode envolver também anormalidades da medula e do sistema geniturinário. Contudo, uma alta variabilidade fenotípica e uma reduzida penetrância têm sido observadas mesmo em casos familiares, o que acaba dificultando tanto o seu diagnóstico como estimativas epidemiológicas precisas sobre sua prevalência ${ }^{(3,6-10)}$. Isto ressalta a importância da investigação mais cuidadosa e detalhada de pacientes portadores de anomalias anorretais e/ou sacrais quanto à possível presença da síndrome ${ }^{(6)}$.

Nesse contexto, o objetivo do presente artigo é relatar o caso de uma criança com a síndrome de Currarino cujo diagnóstico foi feito após avaliação por episódios recorrentes de infecção urinária.

\section{Descrição do caso}

Trata-se de menina branca de dois anos, filha única de pais hígidos, não-consanguíneos e sem história familiar de defeitos congênitos. A mãe apresentava 43 anos e o pai, 32 anos. A criança nasceu de parto normal, com apresentação cefálica, pesando $2070 \mathrm{~g}$ (Percentil, $\mathrm{P}<3$ ), medindo $43 \mathrm{~cm}$ $(\mathrm{P}<3)$, com perímetro cefálico de $31,5 \mathrm{~cm}(\mathrm{P} 2)$, perímetro torácico de $28 \mathrm{~cm}(\mathrm{P} 3-25)$ e Apgar no $1^{\circ}$ minuto de 8 e no $5^{\circ}$ minuto de 9 . A mãe realizou pré-natal e a única intercorrência foi uma infecção urinária tratada com antibioticoterapia. Ela negou o uso de outras drogas ou mesmo de medicamentos com potencial teratogênico. A avaliação ultrassonográfica realizada na gestação, com 15 e 27 semanas, não evidenciou alterações. Imperfuração anal com fístula retovestibular foi diagnosticada no primeiro dia de vida, momento em que a paciente realizou a cirurgia de colostomia. Ela apresentou, ainda, durante o período perinatal, icterícia, sepse e meningite, tratadas respectivamente com fototerapia e antibioticoterapia. A avaliação ecocardiográfica feita devido a um sopro cardíaco evidenciou também uma comunicação interatrial mínima, sem necessidade de intervenção cirúrgica.

Com cinco meses, fez cirurgia de anorretoplastia sagital posterior com revisão da colostomia por apresentar estenose e fístula vestibular. Por volta dos sete meses, começou a apresentar episódios recorrentes de infecção urinária, estabelecendo-se o diagnóstico, por meio da avaliação pela ultrassonografia e uretrocistografia, de bexiga neurogênica associada a um importante refluxo vesicoureteral à esquerda (grau V). Na mesma ocasião, foi constatada a presença de agenesia parcial do sacro (ausência da terceira, quarta e quinta vértebras sacrais) (Figura 1 e 2). Necessitou de antibioticoterapia profilática com nitrofurantoína e de sondagens vesicais de alívio diárias. A avaliação pela tomografia computadorizada (TC) e ressonância nuclear magnética (RNM) de coluna identificou a presença de uma fístula coincidente com a fosseta da transição lombo-sacral, observada ao exame físico (Figura 1), que se obstruía internamente, além de amputação da porção inferior da medula, com diminuição do número de raízes nervosas da cauda equina, e massa pré-sacral de aspecto lipomatoso. A cirurgia de abaixamento do cólon, feita com um ano e dois meses, confirmou que esta tumoração era um lipoma sem comunicação com o canal medular. Nesse meio tempo, a paciente também necessitou de vesicostomia.

A criança não era dismórfica. Aos 11 meses de idade ela apresentava peso de $6690 \mathrm{~g}(<\mathrm{P} 3)$, comprimento de $67 \mathrm{~cm}$ $(<\mathrm{P} 3)$, perímetro cefálico de 44,5cm (P2-50), cílios longos, fendas palpebrais oblíquas para cima, lábio superior fino, além da fosseta lombo-sacral descrita anteriormente, localizada à esquerda da linha média (Figura 1). Seu desenvolvimento neuropsicomotor era adequado para a idade. Não aparentava déficit de força de membros inferiores. Depois disso, ela evoluiu sem intercorrências. Usou nitrofurantoína profilática para infecção urinária. A cintilografia renal realizada posteriormente também mostrou rins normofuncionantes. 


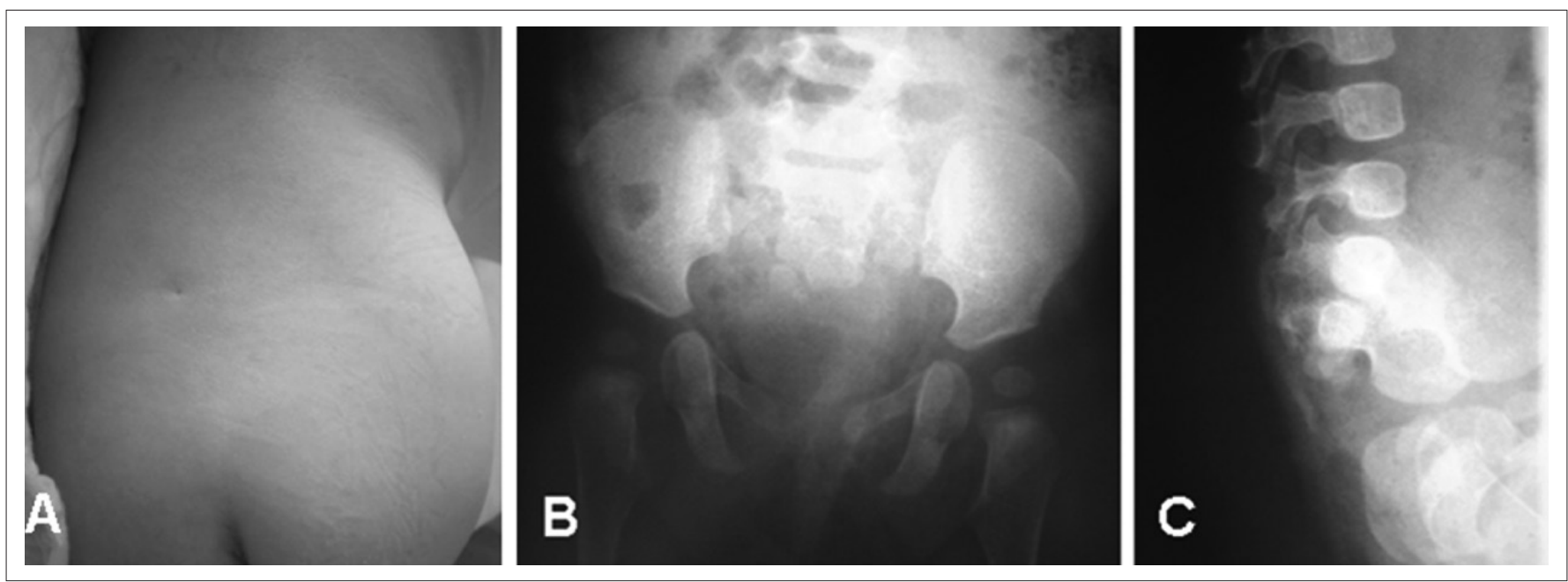

Figura 1 - Imagem do dorso da paciente aos quatro meses de idade (A). Notar a fosseta na transição lombo-sacral à esquerda. Imagem radiográfica da região abdômino-pélvica demonstrando a agenesia parcial do sacro (B e C), com "amputação" da sua porção terminal.

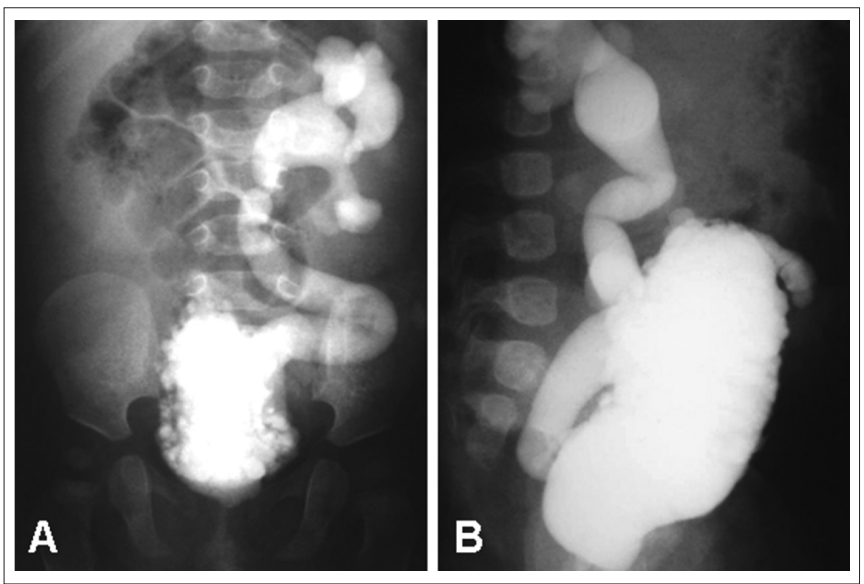

Figura 2 - Uretrocistografia com bexiga neurogênica e importante refluxo vesicoureteral à esquerda ( $\mathrm{A}$ e $\mathrm{B})$

A avaliação citogenética através do cariótipo de alta resolução ( $\geq 550$ bandas) por bandas GTG foi normal. A avaliação clínica e radiológica dos pais não identificou a presença de anormalidades sacrais.

\section{Discussão}

Malformações anorretais são consideradas anomalias congênitas comuns e sua associação com alterações sacrais ocorre em $29 \%$ dos $\operatorname{casos}^{(2)}$. A presença de imperfuração anal com fístula retovestibular, agenesia parcial do sacro e lipoma présacral, anormalidades que formam a "tríade" de Currarino, confirmaram o diagnóstico da síndrome em nossa paciente. O principal sintoma observado nos portadores da síndrome é a constipação crônica, algumas vezes intratável, decorrente das malformações anorretais (cerca de $40 \%$ dos casos). Estas incluem a imperfuração anal, a posição anal ectópica e uma variedade de conexões inapropriadas originárias da região anorretal tanto para a medula espinhal e pele como para o sistema geniturinário (fístulas retovaginais, retocutâneas ou retouretrais) $)^{(2,3,11,12)}$.

As anormalidades do sacro podem ser variáveis, mas sempre há preservação da primeira vértebra sacral (S1). Elas estão presentes em praticamente todos os pacientes e incluem, de uma forma geral, a agenesia parcial do sacro, podendo levar à impressão de um sacro em forma de "foice" ou "crescente" (sinal da "cimitarra"); sacro bífido e "amputado" devido a uma agenesia terminal. Em raras situações, existe apenas um envolvimento coccígeo ${ }^{(3,6,7,13,14)}$. Assim, a radiografia pélvica deve ser feita na avaliação inicial de casos suspeitos ${ }^{(6)}$.

Além de meningoceles ( $50 \%$ dos casos), outras massas pré-sacrais têm sido descritas em cerca de $40 \%$ dos casos e incluem cistos neuroentéricos, dermoides e epidermoides, além de teratomas, hamartomas e lipomas, como observado em nossa paciente. Este último é considerado um achado pouco frequente na síndrome $e^{(2,3,8,11)}$. Neoplasias malignas como teratomas, leiomiossarcomas e tumores neuroendócrinos também têm sido descritas. Além disso, é importante estar ciente de que existe chance, apesar de incerta, de malignização da tumoração. Dessa forma, a realização de ressonância nuclear magnética da coluna é mandatória assim que estabelecido o diagnóstico de síndrome de Currarino, devendo ser repetida periodicamente durante a infância devido ao risco de malignização da tumoração. A radiografia e 
a tomografia computadorizada são consideradas inadequadas para avaliar massas pré-sacrais. Além disso, a ressonância nuclear magnética é o melhor método para prover informações úteis para estabelecer estratégia de tratamento de pacientes com meningocele e anormalidades espinhais. Recomenda-se também, devido ao risco de malignização e de ocorrência de infecções perianais e meningite, a ressecção da massa independentemente de sua natureza ${ }^{(3,4,7-9,12,15-17)}$.

Anormalidades do sistema geniturinário, como a bexiga neurogênica (no caso, secundária à lesão medular), com infecções urinárias recorrentes e a fístula retovestibular, também são comuns. Fazem parte também do seu espectro as duplicações de ureter, o rim duplicado ou em ferradura, o refluxo vesicoureteral, a incontinência urinária, a hidronefrose, o útero bicorno e o septo de vagina. Anormalidades medulares são comuns (estão presentes em $70 \%$ dos pacientes) e consistem principalmente em medula presa, siringomielia, diastematomielia e hidromielia. $\mathrm{O}$ achado de amputação da porção inferior da medula, similar ao observado em nossa paciente, é incomum ${ }^{(2,3,6,8,9,11,13,17)}$.

As malformações observadas na síndrome de Currarino ocorrem em tecidos originários do broto caudal e podem refletir distúrbios da neurulação secundária, um processo que ocorre precocemente durante o desenvolvimento embrionário. Tais distúrbios envolveriam anormalidades na adesão do endoderma e do neuroectoderma, o que causaria uma conexão entre o intestino e a coluna espinhal devido a uma falha na fusão vertebral anterior. Entretanto, a verdadeira anormalidade no processo de embriogênese associado à síndrome permanece desconhecida ${ }^{(4,7,8,11,18)}$. Atualmente, sabe-se que a síndrome de Currarino pode se dever a mutações no gene HLXB9 (bomeobox-HB9), localizado na região 36 do braço longo (q) do cromossomo $7^{(19)}$. Diferentes mutações já foram identificadas nesse gene (até o momento, mais de 60) e todas se associam ao fenótipo da síndrome. Contudo, parece não existir uma correlação direta entre o genótipo e o fenótipo apresentados pelos pacientes. É importante saber que tais mutações do gene HLXB9 se relacionam principalmente a casos familiares, sendo que uma parcela considerável dos indivíduos com a síndrome (cerca de $70 \%$ dos casos esporádicos) não apresenta uma etiologia definida. Esses achados sugerem a possível presença de uma heterogeneidade de loco, ou seja, envolvimento de outros genes como causa para a síndrome de Currarino ${ }^{(3,9,11,13,20,21)}$. Essa condição tem um padrão de herança autossômica dominante, ou seja, um indivíduo afetado possui $50 \%$ de chance de transmitir a doença a seus filhos. Contudo, devido à sua grande variabilidade clínica, alguns pacientes podem apresentar anormalidades assintomáticas, com presença, por exemplo, de agenesia sacral parcial isolada, sendo identificadas somente por exames de imagem (cerca de um terço dos casos). Nesses indivíduos, lesões neurológicas, meningite bacteriana ou degeneração maligna podem ser complicações tardias e graves decorrentes da massa pré-sacral. Essas peculiaridades podem levar a um atraso no diagnóstico, bem como à não-identificação de um possível afetado. Além disso, a "tríade" completa e clássica é rara. Pacientes com a tríade da síndrome de Currarino são usualmente diagnosticados durante a primeira década de vida, ao contrário dos portadores da forma incompleta, que são muitas vezes reconhecidos tardiamente, na idade adulta. Por isso, a síndrome deveria ser considerada mesmo na presença de um fenótipo parcial. Dessa forma, a avaliação tanto clínica quanto radiológica cuidadosa dos parentes em primeiro grau sempre deve ser realizada ${ }^{(3,8,14,17)}$. Em nosso caso, esta foi normal, o que sugere fortemente que a síndrome de Currarino tenha ocorrido devido a uma mutação nova. Contudo, não se pode descartar a possibilidade, apesar de rara, de que um dos pais da paciente seja portador de uma mutação para a síndrome e não apresente anormalidades sacrais devido a uma penetrância incompleta ${ }^{(3)}$. Todas essas considerações são fundamentais para o adequado aconselhamento genético dos pacientes e suas famílias.

Atualmente, é também possível realizar o diagnóstico pré-natal da síndrome de Currarino. A ultrassonografia fetal é capaz de identificar a presença de massa pré-sacral, anomalias do sacro e da medula espinhal, bem como de outras alterações sugestivas, como ventriculomegalia. Esses achados sonográficos podem ser confirmados por meio da ressonância magnética fetal ${ }^{(3,18,22,23)}$. Por outro lado, a análise mutacional, com o estudo do material coletado, por exemplo, através da amniocentese, é capaz de confirmar a presença de mutações familiares já conhecidas ou mesmo de identificar novas alterações do gene HLXB9. Contudo, cabe lembrar que um percentual dos casos familiares da SC, apesar de pequeno, não mostra mutações identificáveis neste gene. Além disso, $70 \%$ dos casos esporádicos não apresentam uma alteração identificável ${ }^{(3,23)}$.

O diagnóstico diferencial da síndrome de Currarino abrange condições nas quais a agenesia sacral pode estar presente, como a síndrome de regressão caudal (OMIM

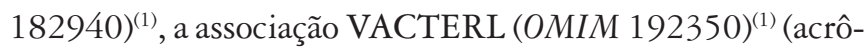
nimo para anormalidades vertebrais, anorretais, cardíacas, traqueoesofágicas, renais e de membros) e o complexo OEIS (OMIM 258040) $^{(1)}$ (acrônimo para onfalocele, extrofia de 
cloaca, ânus imperfurado e anormalidades vertebrais). Cada uma delas pode ser diferenciada da síndrome de Currarino, até com certa facilidade, pelas suas anormalidades específicas associadas ${ }^{(3,9)}$.

Crianças com anormalidades anorretais, como imperfuração e ectopia anal, deveriam sempre ser cuidadosamente avaliadas quanto à possível presença da síndrome de

\section{Referências bibliográficas}

1. Online Mendelian Inheritance in Man, OMIM ${ }^{\circledR}$. [Homepage on the Internet]. McKusick-Nathans Institute of Genetic Medicine, Johns Hopkins University (Baltimore, MD) and National Center for Biotechnology Information, National Library of Medicine (Bethesda, MD), [cited 2010 Jul 19]. Available from: http:// www.ncbi.nlm.nih.gov/omim/

2. Belloni E, Martucciello G, Verderio D, Ponti E, Seri M, Jasonni V et al. Involvement of the HLXB9 homeobox gene in Currarino syndrome. Am J Hum Genet 2000;66:312-9.

3. Lynch SA, Wang Y, Strachan T, Burn J, Lindsay S. Autosomal dominant sacral agenesis: Currarino syndrome. J Med Genet 2000;37:561-6.

4. Fernandes CK, Lopes F, Lobato LF, Ferreira LS, Silveira RT, Teixeira VC et al. The tailgut cyst is an embryological remnant of the retrorectal (Presacral) space that can be a part of the Currarino syndrome. Rev Bras Coloproct 2007;27:446-51.

5. Currarino G, Coln D, Votteler T. Triad of anorectal, sacral, and presacral anomalies. AJR Am J Roentgenol 1981;137:395-8.

6. Martuccielo G, Torre M, Belloni E, Lerone M, Pini Prato A, Cama A et al. Currarino syndrome: proposal of a diagnostic and therapeutic protocol. J Pediatr Surg 2004;39:1305-11.

7. Kilickesmez O, Gol IH, Uzun M, Oruk C. Complete familial Currarino triad in association with Hirschsprung's disease: magnetic resonance imaging features and the spectrum of anorectal malformations. Acta Radiol 2006;47:422-6.

8. Crétolle C, Zérah M, Jaubert F, Sarnacki S, Révillon Y, Lyonnet S et al. New clinical and therapeutic perspectives in Currarino syndrome (study of 29 cases). J Pediatr Surg 2006;41:126-31.

9. Crétolle C, Pelet A, Sanlaville D, Zérah M, Amiel J, Jaubert F et al. Spectrum of $H L X B 9$ gene mutations in Currarino syndrome and genotype-phenotype correlation. Hum Mutat 2008;29:903-10.

10. Bunc G, Ravnik J, Vorsic M, Ravnik M. Variable presentations of Currarino syndrome in three members of the same family. Acta Neurochir (Wien) 2009;151:1169-73.

11. Hagan DM, Ross AJ, Strachan T, Lynch SA, Ruiz-Perez V, Wang YM et al.
Currarino. O diagnóstico da síndrome pode ter implicações especialmente para o momento da cirurgia corretiva se houver presença de massa pré-sacral com indicação de remoção, além de o diagnóstico dirigir a avaliação complementar e proporcionar aconselhamento genético ao paciente e sua família. A agenesia parcial do sacro pode servir como um forte indicador da presença desta entidade clínica.
Mutation analysis and embryonic expression of the HLXB9 Currarino syndrome gene. Am J Hum Genet 2000;66:1504-15.

12. Saberi H, Habibi Z, Adhami A. Currarino's syndrome misinterpreted as Hirschsprung's disease for 17 years: a case report. Cases J 2009;2:118.

13. Köchling J, Karbasiyan M, Reis A. Spectrum of mutation and genotypephenotype analysis in Currarino syndrome. Eur J Hum Genet 2001;9:599-605.

14. Urioste M, Garcia-Andrade Mdel C, Valle L, Robledo M, González-Palacios F, Méndez $\mathrm{R}$ et al. Malignant degeneration of presacral teratoma in the Currarino anomaly. Am J Med Genet A 2004;128A:299-304.

15. Riebel T, Mäurer J, Teichgräber UK, Bassir C. The spectrum of imaging in Currarino triad. Eur Radiol 1999;9:1348-53.

16. Haga Y, Cho H, Shinoda S, Masuzawa T. Recurrent meningitis associated with complete Currarino triad in an adult. Neurol Med Chir (Tokyo) 2003;43:505-8.

17. Turgut $\mathrm{M}$, Cullu E, Ulucan $\mathrm{H}$. Incomplete Currarino triad as an embryological variant. Case report and review of the literature. J Neurosurg 2006;105(6 Suppl):504-7.

18. Eliás P, Zizka J, Balícek P. Currarino triad: concurrent US and MRI diagnosis in the fetus and the mother. Prenat Diagn 2002;22:1005-10.

19. Ross AJ, Ruiz-Perez V, Wang Y, Hagan DM, Scherer S, Lynch SA et al. A homeobox gene, $H L X B 9$, is the major locus for dominantly inherited sacral agenesis. Nat Genet 1998;20:358-61.

20. Wang RY, Jones JR, Chen S, Rogers RC, Friez MJ, Schwartz CE et al. A previously unreported mutation in a Currarino syndrome kindred. Am J Med Genet A 2006;140:1923-30.

21. Volk A, Karbasiyan M, Semmler A, Todt U, Urbach $H$, Klockgether $T$ et al Adult index patient with Currarino syndrome due to a novel HLXB9 mutation, c.336dupG (p.P113fsX224), presenting with Hirschsprung's disease, cephalgia, and lumbodynia. Birth Defects Res A Clin Mol Teratol 2007;79:249-51.

22. Friedmann W, Henrich W, Dimer JS, Bassir C, Kunze J, Dudenhausen JW. Prenatal diagnosis of a Currarino triad. Eur J Ultrasound 1997;6:191-6.

23. Crétolle C, Sarnacki S, Amiel J, Geneviève D, Encha-Razavi F, Zrelli S et al. Currarino syndrome shown by prenatal onset ventriculomegaly and spinal dysraphism. Am J Med Genet A 2007;143A:871-4. 